\title{
FORMAÇÃO ESCOLAR NO CONTEXTO DAS CULTURAS DIGITAIS: DESAFIO DO USO DA INTERNET COMO AMBIENTE DE APRENDIZAGEM NO ENSINO MÉDIO
}

\author{
Jean Mac Cole Tavares SANTOS ${ }^{1}$ \\ Patrícia Cristina de Aragão ARAÚJO²
}

RESUMO: Castels (1999) chama atenção para como as tecnologias digitais trouxeram novo modo de ver e de se articular com o mundo e o próprio sistema vigente viabilizando, como sociedade em rede, novas possibilidades de produzir e disseminar o conhecimento. A partir daí, nossa pesquisa focaliza a prática docente em relação ao uso da internet em sala de aula tomando como referência as incertezas e dilemas que fazem parte da vivência e experiência docente. Este estudo foi realizado com docentes do Ensino Médio das redes estaduais de ensino do Rio Grande do Norte e do Ceará, que admitiram utilizar a internet enquanto recurso pedagógico. Buscamos entender qual relação pedagógica é estabelecida pelo docente com as possibilidades de uso da internet no processo de construção do ensino-aprendizagem em sala de aula. Foi possível perceber que os professores ainda resistem ao uso do computador em sala de aula, por causa das incertezas que essa tecnologia possibilita, trazendo novos desafios para docência.

PALAVRAS-CHAVE: Novas tecnologias. Formação docente. Ciberespaço.

\section{Introdução}

$\mathrm{Na}$ sociedade contemporânea, o desenvolvimento técnico-científico assume importância central. A época atual aparece hegemonizada pela chamada terceira revolução técnico-industrial, na qual os avanços da microeletrônica têm papel preponderante, ocupando cada vez mais os espaços sociais, fato que foi se acentuando desde a década de 70 do século passado.

Com mais força, a crescente inovação tecnológica dos últimos vinte anos, trazendo para a maioria da população o acesso fácil a computadores portáteis interligados à rede mundial de computadores, possibilitou que as novas tecnologias se tornassem um fenômeno interessante de facilitação de informações. Desse modo, a

\footnotetext{
1 Doutor em Educação. UFPB - Universidade Federal da Paraíba. Pós-doutor na Universidade de Valência, Espanha e na UERJ - Universidade do Estado do Rio de Janeiro. Professor Adjunto 4 Faculdade de Educação. UERN - Universidade do Estado do Rio Grande do Norte. Mossoró - RN Brasil. 59610-210 - maccolle@ hotmail.com.

2 Doutora em Educação. UFPB - Universidade Federal da Paraíba. Professora Titular. UEPB Universidade Estadual da Paraíba. João Pessoa - PB - Brasil. 58200-000 - patriciara@ hotmail.com.
} 
sociedade pôde ser rebatizada, pontualmente, de sociedade da informação, termo cunhado por Peter Drucker, ainda nos anos 1960. Assim, é fato que, apesar de atrasos nos setores mais pobres da sociedade, a grande maioria da população começou a ter acesso a uma quantidade incalculável de informações através da internet.

A escola, diante desse quadro, vive momentos de incertezas. Estas incertezas partem das dificuldades de aproximação das relações estabelecidas entre o contexto tecnológico atual e os elementos que rodeiam o processo educativo. As condições materiais de trabalho escolar, a precariedade dos recursos didático-pedagógicos, entre outros aspectos que desafiam cotidianamente a escola, particularmente a escola pública, e a prática pedagógica docente, não condizem com as condições exigidas pela sociedade em questão. Isto é, um mundo tecnológico não admite uma escola, incluindo seu corpo docente, não tecnológica.

Historicamente, as incertezas são enfrentadas pelos governos com reformas, principalmente, curriculares. Com o ensino médio, por exemplo, foi exatamente assim que aconteceu na década final do século passado e nos primeiros anos do novo século. Portanto, as propostas de reforma curricular para essa modalidade de ensino nasceram em resposta às mudanças na esfera do conhecimento e seus desdobramentos no mundo do trabalho e nas relações sociais. Assim, pelo menos, é o discurso que embasa a primeira reforma do ensino médio pós-LDB:

O volume de informações, produzido em decorrência das novas tecnologias, é constantemente superado, colocando novos parâmetros para a formação dos cidadãos. Não se trata de acumular conhecimentos. A formação do aluno deve ter como alvo principal a aquisição de conhecimentos básicos, a preparação científica e a capacidade de utilizar as diferentes tecnologias relativas às áreas de atuação. Propõe-se, no nível de Ensino Médio, a formação geral, em oposição à formação específica; o desenvolvimento de capacidades de pesquisar, buscar informações, analisá-las e selecioná-las; capacidade de aprender, criar, formular, ao invés do simples exercício de memorização. (BRASIL, 1999, p.16).

A rapidez das informações vai sendo superada por causa das novas tecnologias, exigindo do ensino que ele ultrapasse a fase de fixar quantidade de conhecimentos no aluno. A escola precisa formar o aluno para que ele possa construir seu aprendizado, desenvolvendo sua capacidade de adaptação ao novo momento tecnológico.

O discurso, em suma, decreta que a educação precisa responder urgentemente às demandas da denominada revolução da informática, que promove mudanças radicais na 
área do conhecimento. A escola deve absorver as transformações capazes de atender aos novos pressupostos de seu tempo, desenvolvendo uma nova compreensão teórica sobre o seu papel diante do novo paradigma, investindo na formação do novo perfil de que a sociedade e o mercado precisam para se desenvolver (SANTOS, 2008).

Com essa compreensão, foi fácil ver a internet como o instrumento que possibilita contribuir com o aprendizado do aluno de forma autônoma e inovadora. Segundo Furtado (2007, p.23),

\begin{abstract}
A Internet provê acesso imediato a uma quantidade gigantesca de informações científicas, educacionais, culturais e de lazer, em tempo real e de forma direta. A Internet, sendo bem utilizada, pode ser considerada como uma tecnologia de inteligência, ao lado da escrita e da imprensa, porém com um arrebatamento libertador ainda maior por possuir recursos altamente elaborados na recuperação e transmissão da informação.
\end{abstract}

Desse modo, antes de qualquer intervenção empírica, parece claro que não podemos perder a oportunidade pedagógica do uso da internet no processo de pesquisa para aquisição, para assimilação do conhecimento. Vale, no entanto, indagar sobre a percepção dos professores sobre a internet e quais as condições para transformar tal instrumento em aliado na sua atividade profissional. As perguntas então são: como o professor ver essa ferramenta? Como ele se relaciona com ela? Qual a relação pedagógica estabelecida pelo docente com as possibilidades de uso da internet no processo de construção do ensino-aprendizagem? Quais as políticas de apoio (aquisição, formação, acompanhamento) ao docente para uso da internet em suas atividades pedagógicas?

Objetivamos com isso pensar sobre a inserção, no ensino médio, do saber informatizado, do prisma das tecnologias digitais, a partir da internet. Neste sentido, a diretriz que empreendemos neste texto, focaliza a prática docente em relação ao uso da internet em sala de aula tomando como referência as incertezas e dilemas que fazem parte da vivência e experiência docente.

A parte empírica do estudo foi realizada com docentes do Ensino Médio que utilizam a internet enquanto recurso nas ações pedagógicas como forma de propiciar a aprendizagem dos alunos. Entrevistamos 12 (doze) professores de escolas públicas estaduais com atuação no ensino médio na região do Oeste Potiguar, no Rio Grande do Norte, e de Fortaleza, no Ceará. Como instrumento de pesquisa, adotamos o 
questionário semiestruturado buscando deixar o depoente livre para externar sua opinião sobre o assunto, sem os limites e restrições de perguntas fechadas.

Este texto apresenta a seguinte estrutura: primeiro, apresentamos um tópico com a discussão sobre a necessária inclusão das novas tecnologias em sala de aula; depois outro tópico historiando acerca da internet e a abordagem sobre esta em documento oficial, a exemplo, dos Parâmetros Curriculares Nacionais para o Ensino Médio PCNEM (BRASIL, 1999) relacionando as discussões com o referencial que nos aporta, sobretudo a partir dos estudos desenvolvidos, principalmente, por Moran (2007), Furtado (2007) e Castels (1999). Na medida em que o debate é estabelecido, inserimos as narrativas docentes sobre o uso da internet e seu cotidiano, buscando estabelecer as conexões entre o discurso oficial, o debate teórico e a experiência docente. Assim, as falas de nossos depoentes perpassarão os dois tópicos.

\title{
As novas tecnologias de informação e comunicação na sala de aula
}

\author{
Eles respiram internet. \\ Se deixar, não há tempo pra mais nada [...]. \\ Se isso é bom ou ruim, só o tempo dirá. \\ (Entrevistado 11) \\ O mundo todo está ali, disponível. \\ Acaba sendo uma ameaça a disciplina, \\ ao aprendizado deles mesmos. \\ [...] não há limites. É o mundo todo ali.
}

As novas tecnologias de informação e comunicação (TIC) estão presentes no dia a dia da sociedade contemporânea e a escola não pode mais evitar sua presença, seu uso, pois as novas gerações que compõem o contexto da escola interagem cada vez mais com as culturas digitais, sobretudo a internet (FURTADO, 2007). Mesmo que não possamos afirmar, com otimismo ufanista, a positividade do fenômeno, como pondera para o tempo o professor da disciplina de literatura de uma escola de ensino médio em Mossoró, não podemos desconhecer este fato: “[...] os meninos respiram, comem, bebem e até namoram internet [...]. Porque é muito mais atraente, colorida, animada. Não dá para comparar com a nossa voz, o quadro negro e o giz”. Sinal, então, que não podemos ignorar a força das TIC.

Ao invés disso, é preciso reconhecer que uma prática pedagógica permeada pelo uso das TIC pode, do ponto de vista cognitivo, contribuir para a formulação de conceitos e estratégias, possibilitando ao aluno o seu desenvolvimento intelectual. Cabe 
ressaltar que, além do aspecto cognitivo, essas tecnologias também despertam o aspecto afetivo, na medida em que combinam textos, imagens, animações, tornando o processo de aprender mais atraente.

A internet está cada vez mais criativa e interativa. Isso possibilita que o trabalho docente faça uso de blogs, de sites informativos e interativos, de chats, de salas de aula virtuais, da chamada realidade aumentada. A navegação na rede mundial de computadores propicia uma gama de possibilidades, de escolhas, de trajetos, levando o aluno a desenvolver mais autonomia na construção da aprendizagem.

Em suma, as novas tecnologias de informação e comunicação assumem, no contexto da sociedade atual, importância significativa na vida social, atingindo fortemente o cotidiano escolar e a prática docente. Os professores, diante dos constantes dilemas enfrentados nos contextos educativos, são desafiados a elaborarem novos modos de ensinar, utilizando os recursos da internet, enquanto ferramentas que possam lhe dar aporte nas pesquisas e demais atividades de sua prática pedagógica.

Assim, mais do que uma ameaça, o professor precisa perceber que o acesso às informações e a comunicação de maneira rápida e ágil, ocasiona mudanças nos espaços sociais e em diferentes campos do conhecimento entre os quais, a escola. Elas interligam saberes, pessoas e culturas de modo que sujeitos sociais em diferentes contexturas planetárias se articulam, compartilham informações e estabelecem contato. O mundo inteiro, disponível, possível de ser conhecido.

Dessa maneira, nos contextos educativos, as TIC assumem relevante papel, suscitando formas diferenciadas de ensinar e de aprender, visto que elas permitem a interação e integração das pessoas, dos saberes, dos instrumentos, deixando que a escola construa novas formas de sociabilidade, participando das produções construídas em torno das tecnologias digitais. Apesar do risco de clichê, a afirmação correta é que é possível transformar a ameaça em oportunidade.

Os ambientes virtuais de aprendizagem permitem que na escola as informações construídas no mundo social possam ser partilhadas, através de sites, redes sociais, programas educativos, que notabilizem o aprendizado escolar, estimulando o ensinoaprendizagem em diversas áreas do conhecimento que se articulam na escola. São novas habilidades e competências que podem emergir a partir deste novo paradigma de aprendizagem e também de ensino transdisciplinar e interdisciplinar. Este aspecto transdisciplinar é visualizado no espaço virtual quando se congregam diferentes formas 
de saberes e estes possibilitam outros modos de ensino-aprendizagem entre grupos de alunos.

As tecnologias digitais facilitam o trato do conhecimento de maneira interdisciplinar, permitindo inovação nos meios de aprendizagem, em vista que multiplicam as formas como as pessoas tem acesso ao conhecimento de diferentes culturas, povos e línguas. Estes ambientes digitais consistem, pois, em novos espaços de produzir e disseminar o conhecimento.

Castels (1999), chamando atenção para como as tecnologias digitais trouxeram um novo modo de ver e de se articularem com o mundo e o próprio sistema vigente enfatiza que:

\begin{abstract}
A revolução da tecnologia da informação e a reestruturação do capitalismo introduziram uma nova forma de sociedade, a sociedade em rede. Essa sociedade é caracterizada pela globalização das atividades econômicas decisivas do ponto de vista estratégico; por sua forma de organização em redes; pela flexibilidade e instabilidade do emprego e a individualização da mão-de-obra. Por uma cultura de virtualidade real construída a partir de um sistema de mídia onipresente, interligado e altamente diversificado. Admirável ou não, trata-se na verdade de um mundo novo. (CASTELS, 1999, p.17).
\end{abstract}

Tendo em vista este aspecto, este 'novo mundo' criou novos espaços de produção do conhecimento, numa sociedade que se comunica em rede, cujos fluxos de informações trafegam de maneira nunca antes imaginada. Do ponto de vista econômico as mediações entre as sociedades foram agilizadas, tendo em vista as atividades e relações comerciais que foram oportunizadas; de outro ponto de vista tais mudanças evidenciaram também a culminância das instabilidades e desigualdades, sobretudo naquelas relativas ao mundo do trabalho, como a questão da empregabilidade e das condições sociais desiguais que norteiam as realidades sociais de muitas sociedades ao redor do mundo, conforme nos mostra Castels (1999).

Estamos convivendo com múltiplas realidades de tempo, pois diante de um ambiente ungido de virtualidade, o real representado num mundo virtual, ocasionou outro sentido de tempo, o chamado tempo virtual, mensurado pela conexão feita via rede de computadores, nos quais diferentes sujeitos sociais se apropriam destes espaços cotidianamente, para estabelecerem conexão, reconfigurando assim a noção de percepção de tempo e espaço construídos, o virtual, materializado em fios e redes de tecnologias de alta resolução. 
Podemos perceber que esta consiste numa nova forma de pensar a cultura planetária, via a articulação que estes meios de comunicação permitem. Os espaços digitais podem favorecer que em diferentes lugares do planeta pessoas conectadas possam se comunicar, tecer entrelaços de saberes e empreender formas de aprendizagem, estando assim inclusas no mundo tecnológico viabilizadas pela chamada cultura digital.

O desafio docente, primeiro, é entender esse momento, depois agir. Furtar o direito do aluno ao 'novo mundo' tecnológico, em nome da disciplina ou mesmo pelo temor de falta tempo para repassar o conteúdo, pode resultar na dificuldade incluir o discente nessa era digital.

Em tempos de modernidade líquida, como nos coloca Bauman (2007), onde a velocidade ganha espaço na vida moderna, dada a fluidez e o modo como as pessoas agilizam suas vidas e suas relações, se torna de primaz importância refletir sobre a inclusão social a partir da inclusão digital, criando assim identidades de pertencimento aos grupos que se comunicam, interagem e se integram via redes de articulação propiciadas neste fazer humano que é também cultural.

Sacristan (2003, p.49), analisando sobre a cultura, afirma:

Cultura é algo que caracteriza grupos humanos diferenciados e que cada indivíduo assimila de forma única. Isso há de ser considerado pela política e pela educação no mundo interrelacionado que nos aproxima física e simbolicamente a todos, em relação ao que nos une, mas também em relação ao que nos separa.

Tomando as palavras de Sacristan (2003) para pensarmos sobre esta nova configuração do mundo mediante a relação com as tecnologias digitais, sobretudo, com a internet, torna-se mister perceber que em cada cultura, dado o hibridismo como se manifestam as relações sociais e as práticas culturais, conforme nos afirma Canclini (1989), tem um modo de vislumbrar o mundo e assim interpretá-lo. Pensar sobre cultura no percurso das realidades tecnológicas atuais é pensar que diferentes grupos etários, sociais e étnicos, se articulam a esta nova forma de comunicação cultural, de maneira singular, mediatizados por sua percepção cultural e as representações sociais construídas a partir delas (CHARTIER, 2002).

Desse modo, o perigo do 'mundo todo ali' não é absoluto já que a cultura tem função de filtro. Sem diminuir a preocupação do professor, a ação deve ser em direcionar o uso para ações educativas, e nunca minimizar ou temer a ferramenta da 
internet, sempre mais atrativa. Ser mais atrativa do que 'a voz do professor, o quadro e o giz', no entanto, não significa superdimensionar a ferramenta a ponto de anular a função docente, significa antes que o professor precisa estar preparado para intervir nesse novo contexto.

Entretanto, para que os recursos pedagógicos da internet sejam ampliados até a escola, a partir do docente, se faz necessário alguns elementos pontuais no empreendimento desta prática: inicialmente, que sejam disponibilizados os recursos pedagógicos, curso de formação continuada e material didático para as aulas; depois que haja vontade do professor em compartilhar com este novo campo de aprendizagem, repleto de novos significados para sua ação docente; terceiro que a escola tenha e disponibilize, em turmas de variados níveis, computadores e acesso as potencialidades disponíveis pela internet.

\section{O contexto do ensino médio e os espaços educacionais da internet}

O discurso do Ministério da Educação, de necessidade da educação, principalmente do Ensino Médio, acompanhar as novas determinações no mundo, com primazia tecnológica, já dura 20 anos. Ainda nos primeiros anos do Governo de Fernando Henrique Cardoso, quando o ministro da educação era Paulo Renato Souza, o discurso de que o 'mundo mudou', o ensino médio também 'precisa mudar' inundou o ambiente escolar.

Os Parâmetros Curriculares Nacionais do Ensino Médio - PCNEM (BRASIL, 1999), aprovado em 1998, base do 'novo ensino médio', já trazia a ideia de que com as novas tecnologias, a rapidez das informações vai sendo superada, exigindo do ensino que ele ultrapasse a fase de fixar quantidade de conhecimentos no aluno. A escola precisa formar o aluno para que ele possa construir seu aprendizado, desenvolvendo sua capacidade de adaptação ao novo momento tecnológico. Assim, uma sociedade (pósmoderna) firmada na técnica, na ciência e na informação exige uma escola de outro tipo: plural, tecnológica e antenada com o seu tempo (BRASIL, 1999).

Agora, com o ministro Fernando Haddad passando o posto para Aluizio Mercadante, no governo do Partido dos Trabalhadores, apesar das diferenças políticas e ideológicas que mantêm com o antigo governo, o discurso continua pautado na sociedade dominada pela tecnologia. 
Para Bauman (2007), na sociedade moderna líquida, a geração atual - crianças, adolescentes e jovens - conecta-se e mantém, entre si, contato profícuo, formando rede comunicacional, onde há trocas de saberes, de informações, alimentando, assim, diferentes modos de interação com realidades múltiplas. Esta geração, conectada, interage, pesquisa, procura, intenta conhecer sua localidade e o mundo; busca diversão, contatar pessoas, sociabilidade, aprendizagens, de forma geral. Esta geração vem sendo chamada de geração net, como apresenta um professor de uma escola de ensino médio:

Os alunos sabem mais do que a gente. Na verdade sinto-me pressionado a me atualizar, a atualizar minhas aulas, para não ficar pra traz, pra não passar vergonha, já que eles trazem muitas informações [...] informações que acham nas redes sociais, em sites, nas brincadeiras na internet, tipo jogos virtuais. É muito difícil ser professor hoje com informação em toda parte e essa meninada toda antenada, conectada, como eles dizem. (Entrevistado 5).

De fato, à medida que a difusão da tecnologia ocupa espaço na sociedade, logo a escola é chamada a tomar posição. Não dá para permanecer alheia ao fenômeno. A tomada de posição vem antes através dos alunos, procurando se articular, fazer contatos, estabelecer relações de sociabilidades via rede sociais (Entrevistado 8). Depois através da ação docente, quando alguns professores tentam furar o bloqueio da lógica cartesiana de saberes e procuram interligar a aprendizagem com o mundo ao seu redor (MORAN, 2007).

Assim, partimos da assertiva que, aceitando ou não, o ambiente escolar já está impregnado das tecnologias de informação. Elas potencializam um novo saber-fazer dos discentes e isso influi na prática pedagógica docente, pois já não se pode dispensar o potencial que este recurso enseja na escola.

Desse modo, a questão passa pela preocupação de como dominar, direcionar, democratizar, aproveitar pedagogicamente o uso das TICs, principalmente a internet, na escola.

Atento aos movimentos irreversíveis desse momento de desenvolvimento tecnológico, as políticas educacionais e os projetos dos governos estão estimulando e viabilizando cada vez mais esta realidade. O acesso, sempre problema recorrente apresentado pelos professores, está sendo enfrentado por ações pontuais. Para as escolas de ensino médio, devido particularmente a compreensão do momento vivido, o direcionamento para incluir a tecnologia nas mãos de professores é visível (DANTAS, 
2005). Nas duas falas, abaixo, de uma professora da disciplina informática na educação, representa bem o momento:

Acontece que o [acesso ao] computador é hoje o menor dos nossos problemas. Quando cheguei aqui [em 2004] não tinha nenhuma máquina que servisse [...] mal dava para digitar textos. Hoje você ver uma sala dessa lotada de computadores, com programas, jogos educativos, com internet e o mais importante com professor (ela) $e$, ainda, com estagiário [de informática] que sabe mais do que a gente.

Se o problema era ter [computador], agora não é mais... os problemas são outros. Capacitação é um problema, computador pessoal, para o professor levar pra casa [...] nem todo professor tem computador dele [...] bem que vem novidade aí do MEC, dando computador pra todo mundo [que é professor]. (Entrevistado 4).

Como a professora adianta, segundo informações no site do MEC, atualmente, o Ministério da Educação vai investir algo em torno de R\$ 150 milhões, em 2012, na compra de 600 (seiscentos) mil tablets para uso dos professores do ensino médio de escolas públicas federais, estaduais e municipais. O objetivo será o de "possibilitar instrumentos e formação aos professores e gestores das escolas públicas para o uso intensivo" das TICs no processo de ensino e aprendizagem (LORENZONI, 2012).

Segundo a propaganda oficial, o mundo evolui em direção a uma sociedade do conhecimento e a escola tem que acompanhar esse processo, porém, sem substituir a relação professor-aluno, já que a tecnologia não é um objetivo em si mesmo, mas parte da estratégia para que a escola possa formar, preparar essa nova geração para o uso de tecnologias da informação. Assim, a eficiência do uso das novas tecnologias depende dos cuidados pedagógicos e do envolvimento dos professores no processo de informatização.

A matéria ainda registra que a doação dos tablets é parte de um projeto que inclui ainda um completo sistema tecnológico, equipamentos desenvolvidos pelo MEC, que reúne projeção, computador, microfone, DVD, lousa eletrônica e possibilidade de acesso à internet, e o próprio tablet. Todo o equipamento, acredita o MEC, permitirá ao professor trabalhar os conteúdos disponíveis em uma parede ou quadro rígido, sem a necessidade de manuseio do teclado ou do computador.

Com o investimento estatal, principalmente para as escolas de ensino médio, o problema do acesso parece superado. Vale salientar, que na entrevista realizada nesta pesquisa, somente dois professores ainda acharam limitada a questão do acesso aos 
computadores e mais um considerou frágil e insuficiente o sistema de acesso a internet, devido a instabilidade de sinal de uma operadora. Mesmo assim, há reconhecimento de todos os entrevistados que o acesso deixou de ser problema para a utilização dessa tecnologia na educação. Os problemas são de outra ordem, como apresenta o depoimento abaixo:

Todo mundo usa, só não usa quem não sabe, mesmo assim tem o pessoal aqui para auxiliar como eu e o técnico [o estagiário em informática]. Aí começa o grande problema: nem sempre dá para atender todo mundo no tempo que eles querem [...] muitos professores ficam com raiva da gente, acha que é má vontade, que dou preferência a um e outros não. Gera atrito. Acontece que, como eu já disse, ter o computador não é mais problema. Precisa capacitar os professores [...] precisa mudar a mentalidade [dos professor] de ter tudo na mão [...] tudo arrumadinho [...] muitos não sabem nem ligar a tela [...] complicado! (Entrevistado 4).

É importante citar, aproveitando a queixa do professor acima, que para não ficar somente na doação dos equipamentos, o MEC oferecerá cursos de formação aos professores através do ProInfo (Programa Nacional de Informática nas Escolas). Os 600 mil professores que lecionam no ensino médio terão à disposição um curso de 360 horas para trabalhar com as novas mídias.

Mesmo sem aprofundar muito essa questão, podemos deduzir que o problema de capacitação deverá continuar. A cultura docente, a cultura do currículo e da autoridade e da disciplina, e outros aspectos que exploraremos mais adiante, não mudarão com cursos eventuais, com capacitações aligeiradas.

Porém, com esta política, com a doação dos equipamentos e a formação dos docentes, o ministério responde ao discurso, já insistente para o ensino médio, de que a escola deve atender às determinações do mundo contemporâneo, onde a tecnologia é fundamental para o desenvolvimento humano na atual fase de desenvolvimento do capitalismo mundial. Uma rendição, se não tardia, inevitável.

Parece claro, no entanto, que a disposição do governo atual em fazer valer seu discurso é maior do que aconteceram nas outras reformas, já que investe uma razoável soma nos equipamentos e na formação. A questão, porém, passa pelas condições dos professores de realmente lidar com essa tecnologia. Como percebem sua contribuição para o bom uso pedagógico dos equipamentos? Qual o preparo docente para enfrentar o desafio pedagógico de uso das tecnologias? 
Dizer que o professor simplesmente não quer [usar as novas tecnologias] é maldade minha. Ele não sabe, não tem tempo, não tá preparado, acostumado com esse mundo [...] falta ideia de relacionar o aprendizado, o conteúdo, com a pesquisa na internet [...] porque não é só jogar os alunos aqui na sala com a internet. Os alunos vão adorar [...] mas [não vão] aprender nada que presta [...] vão ficar no batepapo, conversando, falando besteira, de futebol, namoro e outras coisas piores. (Entrevistado 4).

Falta, como bem apresenta a professora, relacionar o uso da ferramenta com a perspectiva pedagógica. Nisso, não é situação simples de resolver já que depende de formação continuada, de tempo para qualificação, de investimento na profissionalidade docente. Um pouco de conhecimento da realidade das escolas e dos profissionais que lá atuam deixam as expectativas não tão positivas. Nas palavras de Pretto (2005, p.189),

[...] vemos que as escolas estão abandonadas, os professores sem condições de trabalho, salário e formação; estão, portanto, em condições frágeis para responderem criticamente à forte pressão, por um lado, das indústrias de equipamentos e cultura e, por outro, dos próprios estudantes, no sentido de incorporarem os novos recursos do mundo da comunicação e informação. Em função dessa fragilidade, essa incorporação dá-se, na maioria das vezes, sem uma reflexão crítica sobre as suas reais necessidades, objetivos e possibilidades.

Apesar de apontar avanços no processo de disponibilizar os meios e, quiçá, a formação necessária, outros elementos encontrados na realidade escolar destoam do otimismo do ministério, aprofundando a preocupação da professora entrevistada. Temos, então, duas sérias questões: a primeira diz respeito às condições da profissão docente revelada por Pretto (2005) e endossada pela fala abaixo do Entrevistado 3:

Não é porque não quero fazer um curso desse. Quem é que não quer estudar, melhorar o desempenho, capacitar [...]? Agora, ofertar curso e não dar condições dignas de trabalho de nada vai serve [...]. Nenhum professor vai deixar de fazer suas coisas, de cumprir seus horários em outro emprego para se capacitar. Todo mundo tem outras ocupações, outro emprego, até para completar o salário que é muito pouco. Não posso ir [...] não tem como [...].

Por mais redundante que possa parecer, a questão volta para as condições de trabalho, para a precarização da profissão docente e para a denúncia contra os baixos salários dos professores. Sem que sirva de justificativa ou acomodação, não podemos enfrentar o desafio da qualidade, e mais em tempo de inclusão digital nas escolas, sem a perspectiva de lutar pelo reconhecimento e valorização do professor. Mais do que 
nunca, a luta por condições dignas de trabalho, é a luta pela incorporação tecnológica na escola.

$\mathrm{Na}$ primeira questão, podemos afirmar que não é possível resolver uma complexa situação de relação entre tecnologias e escolas somente com ações pontuais. É necessário tratar a questão do uso das novas tecnologias, entre elas a internet, no mesmo bojo da profissão docente e da valorização da escola pública, “[...] pois não adianta propor curso de formação se não arranjar tempo pro professor cursar" (Entrevistado 3). O investimento, se não for generalizado, atendendo aspectos como melhoria salarial, condição de capacitação permanente dos profissionais e o fim da precarização do magistério, com docentes sendo forçados a trabalharem turnos consecutivos para completarem renda, a situação, por paliativa, não resolverá a questão.

A outra questão a ser problematizada, aproveitando a fala do Entrevistado 2, a seguir, tem a ver com a ideia de que "[...] há um enorme conteúdo a ser ministrado, que no final todo mundo será cobrado pelo conteúdo dado e não pela inclusão tecnológica” realizada na escola, pois “[...] sem aprendizagem não há educação, nada disso faria sentido, nem computador, nem escola, nem professor [...]”. Desse modo, a segunda questão, que não está de forma alguma desligada da primeira, mira a condição pedagógica de entender o uso da internet como parte curricular.

A busca para colocar as novas tecnologias no lugar de destaque que merece na escola, exige a superação do espírito positivista de nossa concepção de currículo, de aula, de aprendizagem, Segundo Moran (2007, p.2):

O conceito de curso, de aula também está mudando. Hoje, ainda entendemos por aula um espaço e um tempo determinados. Mas, esse tempo e esse espaço serão, cada vez, mais flexíveis. O professor continuará 'dando aula', de uma forma menos informativa e mais gerenciadora, utilizando as possibilidades que as tecnologias interativas proporcionam: para alimentar continuamente os debates e pesquisas com textos, páginas da Internet, até mesmo fora do horário específico da aula, receber e responder mensagens dos alunos, criar listas de discussão etc. Há uma possibilidade cada vez mais acentuada de estarmos todos presentes em muitos tempos e espaços diferentes. Assim, tanto professores quanto alunos poderão estar motivados, se entenderem a 'aula' como pesquisa e intercâmbio. Nesse processo, o papel do professor vem sendo redimensionado e cada vez mais ele se torna um supervisor, um animador, um incentivador dos alunos na instigante aventura do conhecimento. 
Será impossível construir os 'cuidados pedagógicos' com a noção que temos de aprendizagem, de escola e de disciplina. Seremos antiquadros com bastão nas mãos apontando para lousas virtuais. Nosso aluno não acompanhará a dinâmica de poder tudo no ambiente virtual, e nada na relação com seus saberes, com sua construção de aprendizado, com sua dimensão não-linear de currículo.

Portanto, há necessidade de que as barreiras de ordem administrativa e pedagógica sejam ultrapassadas, para que o sistema fragmentado se dilua e a abordagem integradora dos conteúdos, voltados para a elaboração de projetos temáticos, seja desenvolvida com os alunos. $\mathrm{O}$ desafio é enorme, pois falamos de integração efetiva das tecnologias no currículo, de modo que elas sejam incorporadas às práticas pedagógicas docentes. (TEZANI, 2011, p.44).

Dessa forma, faz-se necessário além de outra concepção de educação, a constituição de um novo conceito de professor, com funções equilibradas entre a função de despertar, de orientar o aprendizado e o de permitir o desenvolvimento autônomo dos sujeitos aprendentes, numa nova relação com o currículo escolar. Nesse sentido, a escola precisa rever seus processos de organização, flexibilizar seus currículos, adaptarse a novas situações, formar seus docentes no gerenciamento da aprendizagem com as tecnologias telemáticas (MORAN, 2007, p.3).

\section{Considerações finais}

Sabemos que nas escolas de ensino médio nem sempre o docente tem acesso as novas tecnologias, ao computador, à internet. Mas detectamos que o acesso aumentou bastante e em muitos casos já faz parte da cultura profissional e escolar. As políticas governamentais dos últimos anos, nesse ponto, tem conseguido atingir, mesmo que parcialmente, os objetivos propostos. O engodo, porém, continua na formação, no preparo dos docentes para o manuseio. Sem uma sólida e continuada formação para o entendimento e uso das novas tecnologias, estaremos sempre atrasados em relação ao conhecimento que tem os nossos alunos. Sem dominar a tecnologia, sem a compreensão pedagógica do uso das TIC, seremos levados pelos interesses imediatista dos jovens alunos.

Outro grave problema, pelo menos pelo nosso ponto de vista, diz respeito à essa muleta que a escola e o professor não consegue largar, chamada grade curricular, conteúdo ou mesmo currículo escolar. Chame como quiser, essa ideia fixa que é 
necessário passar um conteúdo ao aluno, aquele que está na apostila ou no livro, não condiz com um mundo aberto de possibilidades de aprendizagem, de interação e de construção de saberes. Rever a cultura do currículo não é ação fácil, mas é uma necessidade inadiável.

Por fim precisamos bater mais uma vez em uma velha tecla. Não fazemos nenhuma inovação na educação sem cuidar da profissionalidade docente. Com subprofissionais, com professores de aluguéis, com horistas, com docentes precarizados, sub-remunerados, não faremos as mudanças curriculares, a mudança de mentalidade, a capacitação docente verdadeira, necessária aos novos tempos de inclusão digital.

Os desafios são hercúleos. No entanto, podemos apreender alguns elementos que podem sinalizar para o sucesso da busca, para a conquista de uma escola culturalmente diversa, humana, acessiva, de todos e digitalmente inclusiva. Durante o desenvolvimento das entrevistas fomos anotando as palavras que mais eram pronunciadas por nossos depoentes e pelos bolsistas no debate sobre as novas tecnologias, sobre os caminhos para o ensino médio e sobre os rumos da sociedade atual, de forma geral. Palavras e expressões como medos, incertezas, perigos, despreparo, carência, ausência estiveram lado a lado com outras como possibilidades, desejos, vontades, capacitação, interação, disposição, mudança, desafios, valorização docente e discente e, principalmente, com a palavra luta. Nem uma delas é caminho único, suficiente em si. Mas com o encontro delas, dialeticamente, podemos perceber que o processo, por ser construção social, caminha para a irreversibilidade do processo. A escola de ensino médio, principalmente a pública, em nome de nossos jovens que dela usufruem, agradece.

\section{SCHOOL EDUCATION IN THE CONTEXT OF DIGITAL CULTURES: THE CHALLENGE OF USING THE INTERNET AS A LEARNING ENVIRONMENT IN SCHOOL}

\footnotetext{
ABSTRACT: Castels (1999) calls attention to how digital technologies have brought new way of seeing and interacting with the world and enabling existing system itself, as the network society, new possibilities of producing and disseminating knowledge. From there, our research focuses on teaching practice in relation to internet use in the classroom with reference to the uncertainties and dilemmas that are part of the experience and teaching experience. This study was carried out with high school teachers of the state system of education in Rio Grande do Norte and Ceará, who admitted using the Internet as a teaching resource. We seek to understand what pedagogical relationship is established by the teacher with the possibilities of Internet use in the construction process of teaching and learning in the classroom. It was
} 
possible to see that teachers still resist the use of computers in the classroom, because of the uncertainties that this technology enables, bringing new challenges to teaching.

KEYWORDS: New technologies. Teacher education. Cyberspace.

\section{REFERÊNCIAS}

BAUMAN, Z. Tempos líquidos. Rio de Janeiro: Jorge Zahar, 2007.

BRASIL. Ministério de Educação. Parâmetros curriculares nacionais: ensino médio. Brasília: MEC/SEMTEC, 1999.

CANCLINI, N. G. Culturas híbridas: estratégias para entrar e sair da modernidade. São Paulo: EDUSP, 1989.

CASTELS, M. A sociedade em rede. Rio de Janeiro: Paz e Terra, 1999.

CHARTIER, R. À beira da falésia: a história entre a incerteza e a inquietude. Tradução de P. C. Ramos. Porto Alegre: Ed. da UFRGS, 2002.

DANTAS, A. S. A formação inicial do professor para o uso das tecnologias de comunicação e informação. Holos, Natal, ano 21, v.1, p.13-26, mai. 2005.

FURTADO, C. A internet como fonte de pesquisa para alunos do ensino fundamental e médio. In: 13 CONGRESSO DE LEITURA DO BRASIL, 2001, Campinas. Anais.... Campinas: Ed. da Unicamp, 2001.

LORENZONI, I. Tecnologia na educação. Ministério distribuirá tablets a professores do ensino médio. Brasília: Ministério da Educação, 2012. Disponível em: <www.mec.gov.br>. Acesso em: 12 mai. 2012.

MORAN, J. M. Como utilizar a internet na educação. Revista Ciência da Informação, São Paulo, v.26, n.2, p.146-153, mai./ago. 2007.

PRETTO, N. L. Tecnologia e novas educações. Salvador: EDUFBA, 2005.

SACRISTAN, J. G. Educar e conviver na cultura global: as exigências da cidadania. Porto alegre: ARTMED, 2003.

SANTOS, J. M. C. T. De novo ensino médio aos problemas de sempre - entre marasmos, apropriação e resistência escolar. Fortaleza: Edições UFC, 2008.

TEZANI, T. C. R. A educação escolar no contexto das tecnologias da informação e da comunicação: desafios e possibilidades para a prática pedagógica curricular. Revista FAAC, Bauru, v.1, n.1, p.35-45, abr./set. 2011. 